\title{
The Monitoring of a Severe Convective Case in Bohai Sea Area on August 31,2015
}

\author{
Yanjiang Li Yanjun Zhou
}

The ocean observatory of Qinhuangdao, Qinhuangdao Hebei 066000, China

\section{${ }^{u 16} 15-08-31$ 渤海强对流天气监测事实 \\ 李延江 周艳军 \\ 秦皇岛海洋气象台, 河北秦皇岛, 066000, 中国}

\begin{abstract}
using the synchronous data such as weather radar, oceanic WRF model etc., a severe convective weather process has been analyzed on August 31, 2015 in Bohai Sea area, the results show that the shear line moved eastward and enhanced at the $925 \mathrm{hPa}$ and $850 \mathrm{hPa}$ in Bohai Bay from 08: 00 to 20: 00, the index $\mathrm{K}$ was $35{ }^{\circ} \mathrm{C}$, index SI was $-1.81{ }^{\circ} \mathrm{C}$, the CAPE was $166 \mathrm{~J} / \mathrm{kg}$ and the vertical wind shear was $16 \mathrm{~m} \bullet$ $\mathrm{S}^{-1}$ in the stratification curve at 08:00 A.M,because of this background, the severe convective weather occurred in Tianjin. The shear line moved northward at the $925 \mathrm{hPa}$ of the lower lay from 20:00P.M on August 31to 08:00A.M on September 1, the convective instability energy increased, several severe convective storm cell of meso- $\gamma$ scale and meso- $\beta$ scale near the shear line have been induced in the central area of Bohai Sea,the new round of the was caused by a series of effecting of radar echo. severe weather process CAPE was released by the strong vertical movement and water vapor convergence of the boundary layer, the cut-in of weaker dry and cold of $\Delta \theta$ se (850-500 hPa) corresponded with the happening and impact area of the convection system in north of Liaodong bay.
\end{abstract}

Keywords: severe convection of Bohai Sea, shear line, a series of effecting of radar echo, the cut-in of dry and cold style

\section{摘要}

利用多部天气雷达、渤海强对流监测等同步资 料, 对 2015 年 8 月 31 日渤海一次强对流天气 过程进行综合分析, 结果表明: 08 时 -20 时渤 海湾一线 925-850 百帕切变线东移增强, 08 时临近探空 $\mathrm{K}$ 指数 $35^{\circ} \mathrm{C}$ 、SI 指数 $-1.81^{\circ} \mathrm{C}$ 及 $\mathrm{CAPE}$ 为 $166 \mathrm{~J} / \mathrm{kg}$, 垂直风切变 $16 \mathrm{~m} \bullet \mathrm{s}^{-1}$, 导致 天津一线的强对流天气发生。20-02 时其前部 低层 925 百帕“切变线” 北抬, 对流性不稳定 能量增强, 在渤海中部的切变线附近诱发多个 中y、 $\beta$ 尺度强对流风暴单体, 在雷达回波 “列车效应”下, 造成了秦皇岛近海新一轮强 对流天气过程。强垂直运动和边界层水汽辐合 触发 CAPE 的释放; 在辽东湾北部 $\Delta \theta \mathrm{se}(850-500 \mathrm{hPa})$ 较弱干冷切入与对流系 统的发生、落区有一定对应关系。

关键词: 渤海强对流; 切变线; 回波 “列车效 应”; 干冷切入

1. 引言

2015 年 8 月 31 日 20 时 -9 月 1 日 04 时, 渤海西海岸带天津至-秦皇岛渤地区出现了 由强对流天气引发的短时暴雨、大风及持续 性雷电天气, 其中, 大风区域出现山海关海 区, 风速最大为 $21.8 \mathrm{~m}^{\cdot} \mathrm{s}^{-1}$; 短时暴雨分别 出现在天津和秦皇岛, 小时雨量最大达 $40 \mathrm{~mm}$; 雷电过程持续时间达 $6 \mathrm{~h}$ 以上。较强 的强对流天气系统对区域经济会造成较大 影响, 直接威胁港口设施及船舶通讯安全, 尤其是 2015 年 6 月 1 日长江监利水域 “东 方之星” 强对流天气引发重大沉船事故之 后, 近海强对流天气监测与预警成为目前社 会关注的焦点之一。卢焕珍 ${ }^{[3]}$ 等人借助塘沽 


\section{Risk Analysis and Crisis Response in Big Data Era (RAC-16)}

天气雷达和自动站对产生海岸带雷暴大风 的对流风暴进行个例分析, 总结出雷暴大风 雷达回波的主要形态、大风来临前径向速度 场有辐合特征等; 王彦 ${ }^{[4]}$ 、贺教 ${ }^{[5]}$ 、郭庆利 ${ }^{[6]}$ 、孙素琴 ${ }^{[7]}$ 等应用卫星资料、多普勒雷达、 闪电等监测资料对近年来海岸带-近海发生 强对流天气个例进行分析, 得出强对流系统 中地闪、云顶亮温与雷达回波关系及 “列车 效应” 引发短时暴雨成因等; 上述分析均以 单部雷达监测分析为主, 对回波源发生及演 变规律的描述存在着一定的局限性, 缺少多 部雷达监测网资料与数值模拟共性分析。利 用五部天气雷达拼图、渤海逐小时强对流监 测及海洋 WRF 模式产品等资料, 综合分析入 海前后的强对流系统时空尺度演变特征; 为 提升渤海强对流天气预警能力提供技术支 撑。

\section{2. 天气背景与实况}

渤海位于中高纬度之间, 受高层大气西 风带影响较大, 大多数不同尺度的强对流天 气系统是由陆地移向海区的, 并在不同的海 岸带区域获取新的能量, 重新加强发展, 影

响新的海岸带直至内陆区域, 它的生、 消及演变规律仅是天气尺度背景下的一个 中尺度天气过程。

\section{1 天气背景}

在 2015 年 8 月 31 日 08 时 (CST) $500 \mathrm{hPa}$ 高空图上 (略) 环渤海上空为弱冷空气配合 的减弱低槽, 对应 08 时 (CST)



图 1.a 2015 年 8 月 31 日 08 时 (CST) 和图 1.b 2015 年 8 月 31 日 20 时 (CST) 为 $925 \mathrm{hPa}$ 风场（单位 $\mathrm{m}$ • $\mathrm{s}^{-1}$ ) 温度场 (单位 ${ }^{\circ} \mathrm{C}$ )

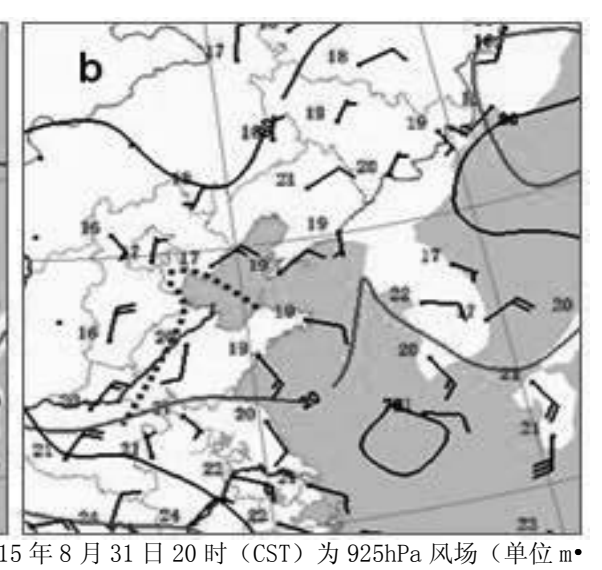

低层 925hPa 高空图上（图 1. a）渤海中南 部为暖空气配合的 “人字型” 切变线, 其中 渤海湾至莱州湾一线温度场有明显暖湿平 流, 这种 “上冷下暖” 垂直结构有利于对流 天气的发生发展, 在低层切变线动力、水汽 耦合下, 给未来强对流天气强度加强提供了 必要条件。直至 20 时低层 $925 \mathrm{hPa}$ 高空图上

（图 1.b) 渤海中南部 “人字型” 切变线原 地旋转, 前部暖式切变线北抬至渤海中部, 导致新一轮强对流天气生成发展, 中尺度系 统沿东南向西北部海岸带延伸发展。从天气 背景分析明显看出: 整个过程分为两个时 段, 即 31 日 08 时-20 时 “人字型” 切变线 造成天津海岸带强对流天气，31 日 20 时-9 月 1 日 02 时 “人字型” 切变线前部暖式切 变为秦皇岛海岸带强对流天气主要影响系 统。

\section{2 强对流实况与探空}

对应实况与探空可分为两个不同时空 尺度见 (图. 2)。第一阶段为 2015 年 8 月 31 日 08 时-20 时, 天津至渤海湾出现了由强对 流天气引发的短时暴雨、持续性雷电天气, 小时雨量最大达 $39 \mathrm{~mm}$; 08 时临近探空 (乐 亭站) $\mathrm{K}$ 指数为 $35^{\circ} \mathrm{C} 、 \mathrm{SI}$ 指数为 $-1.81^{\circ} \mathrm{C}$ 及 $\mathrm{CAPE}$ 为 $166 \mathrm{~J} / \mathrm{kg}, 0-6 \mathrm{~km}$ 垂直风切变 $16 \mathrm{~m}$ ・ $\mathrm{s}^{-1}$, 达到一般强对流系统发生、发展阈值或 临界值。第二阶段为 2015 年 8 月 31 日 20 时-9 月 1 日 02 时, 秦皇岛一山海关出现海区 强对流引发的短时暴雨、大风及持续性雷电 


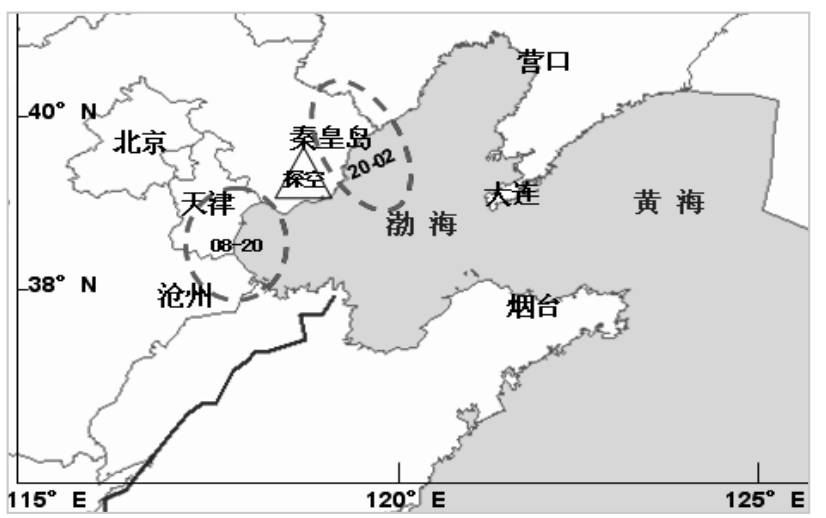

图. 2 红色圆圈表示 08-20 时和 20-02 时（CST）强对流天气落区, $\triangle$ 探空站位置。

天气，大风区域出现山海关海区, 风速最大 为 $21.8 \mathrm{~m} \cdot \mathrm{s}^{-1}$; 雷电过程持续时间达 $6 \mathrm{~h}$ 以 上。20-02 时其前部低层 925-850 百帕切 变线北抬, 20 时 $\mathrm{K}$ 指数 $32^{\circ} \mathrm{C}$, SI 指数 为 $1.36^{\circ} \mathrm{C}, \mathrm{CAPE}$ 为 $383 \mathrm{~J} / \mathrm{kg}$, 垂直风切变 为 $19 \mathrm{~m} \cdot \mathrm{s}^{-1}$, 对流性不稳定能量进一步增强, 海区冷暖空气交汇于渤海中部的切变线附 近, 有利于秦皇岛海岸带新一轮强对流天气 发生。

\section{3. 渤海中尺度天气雷达拼图}

目前, 在渤海海岸带新一代天气雷达有 六部, 如上 (图.2) 秦皇岛、天津、沧州、 烟台、大连及营口等。单部雷达 0.5 仰角, 理论上基本反射率监测半径 $230 \mathrm{~km}$, 径向速 度 $115 \mathrm{~km}$, 由于天线高度不一致和地物折 叠, 监测距离底高在渤海中部区域大于 $1.1 \mathrm{~km}$, 实际综合监测能力为 $150 \mathrm{~km}$ 左右。 对强对流天气发生、发展及演变规律研究有 局限性, 综合拼图与资料共享的实现 (互联 网拼图 10 分一幅) 提升了中尺度系统的监 测能力和技术水准。

3.1 天津一线强对流天气系统入海前后的演 变特征

对照上述同步实况及天气分析, 第一轮 强对流发生时间段为 8 月 31 日 15-18 时 (CST), 见 (图 3. a1) 在渤海湾一带生成的 多单体风暴稳定少动, 雷达反射率因子强回 波带水平尺度 $230 \times 80 \mathrm{~km}$, 强度 40-50 dbz, 移 向 $\mathrm{W} \rightarrow \mathrm{E}$ 向, 移速为 $20 \rightarrow 30 \mathrm{~km} / \mathrm{h}$, 对应天气短
时强降水、雷电等; 2 小时后东移莱州湾维 持发展, 强回波面积缩小, 水平尺度 $180 \times$ $70 \mathrm{~km}$, 强度维持 $40-50 \mathrm{dbz}$, 移向 WSW $\rightarrow$ ENE 向, 移速为 $20 \rightarrow 30 \mathrm{~km} / \mathrm{h}$, 对应天气短时强降水、 雷电、大风等; 天津至渤海湾为一般阵雨天 气。但从莱州湾至渤海湾北部 (图 3. a3) 所 谓 “暖式切变线” 回波带已经初步形成, 并 缓慢向中部海区推进。

3.2 秦皇岛一线强对流天气雷达回波 “列车 效应”

初步生成的渤海南部中尺度强对流回 波带在 31 日 20 时-22 时继续北抬发展, 见

（图 4.b1）雷达反射率强回波带水平尺度 $350 \times 80 \mathrm{~km}$, 强度 $40-55 \mathrm{dbz}$, 移向 $\mathrm{SSW} \rightarrow \mathrm{NNE}$ 向, 移速为 $30 \rightarrow 40 \mathrm{~km} / \mathrm{h}$, 影响范围: 莱州湾唐山海岸带, 对应天气短时强降水、大风、 雷电等; 在渤海中部的切变线附近诱发多个 中y、 $\beta$ 尺度强对流风暴单体 21 时 (图 b2),

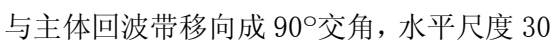
$\times 50 \mathrm{~km}$, 强度 $50-55 \mathrm{dbz}$, 移向 $\mathrm{SE} \rightarrow \mathrm{NW}$ 向, 移 速为 $50 \rightarrow 60 \mathrm{~km} / \mathrm{h}$, 具有明显的向前传播线性 特征, 即雷达回波 “列车效应”。23 时-02 时渤海低层水汽被暖式切变线西南气流源 源不断地输送到辐合线上空, 有利于中小尺 度对流单体及其次级垂直环流的维持、发展, 且这些次级环流规则排列, 从而"列车效应" 得以维持, 造成了秦皇岛近海新一轮强对流 天气过程。 
Risk Analysis and Crisis Response in Big Data Era (RAC-16)

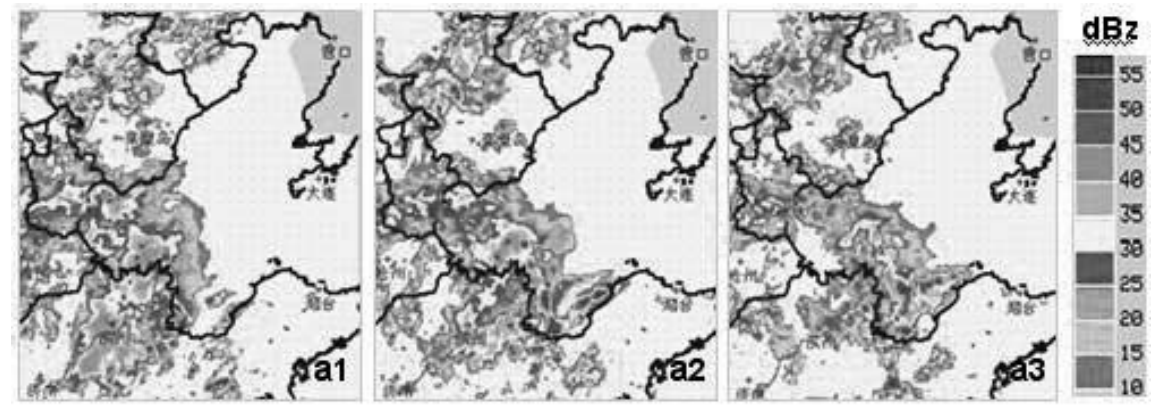

图 3.2015 年 8 月 31 日 16 时-18 时 (CST) 五部天气雷达基本反射率拼图, 时间间隔 1 小时

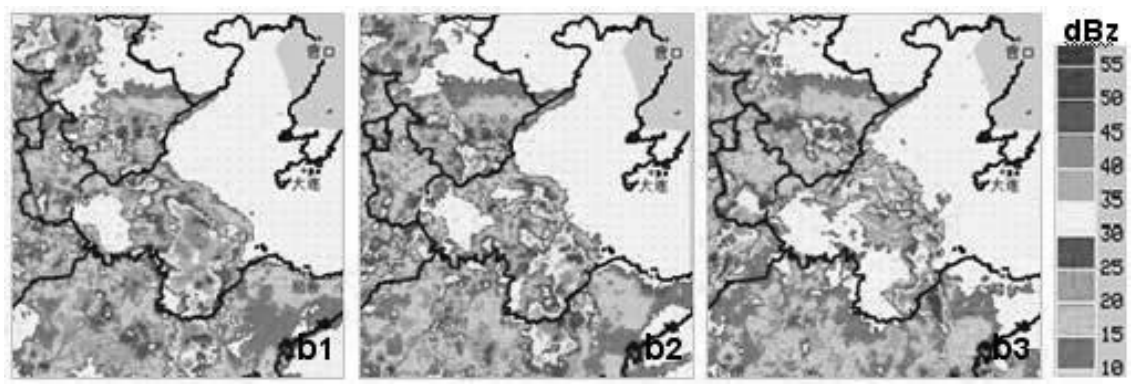

图 4. 2015 年 8 月 31 日 20 时-22 时（CST）五部天气雷达基本反射率拼图, 时间间隔 1 小时

3.3 秦皇岛海区回波带消亡阶段演变特征

从 (图. 5c2) 中明显看出 03 时 (CST) 中部海区回波带出现断裂, 强度下降至 30-40dBz, 04 时趋于趋于消亡, 为一般阵雨 天气。值得关注的是在渤海湾南部沧州海区 有新的强对流回波带生成, 见( 图 5.c2、c3) 水平尺度 $100 \times 40 \mathrm{~km}$, 强度 $45-50 \mathrm{dbz}$, 移向 $\mathrm{N}$ $\rightarrow S$ 向, 移速为 $35 \rightarrow 40 \mathrm{~km} / \mathrm{h}$; 整体中尺度回 波具有螺旋状特点, 相对秦皇岛海区处于消 亡阶段, 进入渤海湾的后部下沉气流垂直于 沧州海海岸带, 摩擦辐合是对流天气发生的
主要动力因素, 由于尺度偏小, 所以持续时 间不足 2 小时。

\section{4. 结论}

(1) 环渤海地区天气尺度系统的有效配置 为不同时段的中尺度对流系统发展提供了 环流背景条件。0 8 时 -20 时渤海湾一线 925-850 百帕切变线东移增强, 08 时临近探 空 $\mathrm{K}$ 指数 $35^{\circ} \mathrm{C}$ 、SI 指数 $-1.81^{\circ} \mathrm{C}$ 及 $\mathrm{CAPE}$ 为 $166 \mathrm{~J} / \mathrm{kg}$, 垂直风切变 $16 \mathrm{~m} \bullet \mathrm{s}^{-1}$, 导致天津一 线的强对流天气发生。20-02 时其前部低层 925 百帕 “暖式切变线” 北抬, 对流性不稳

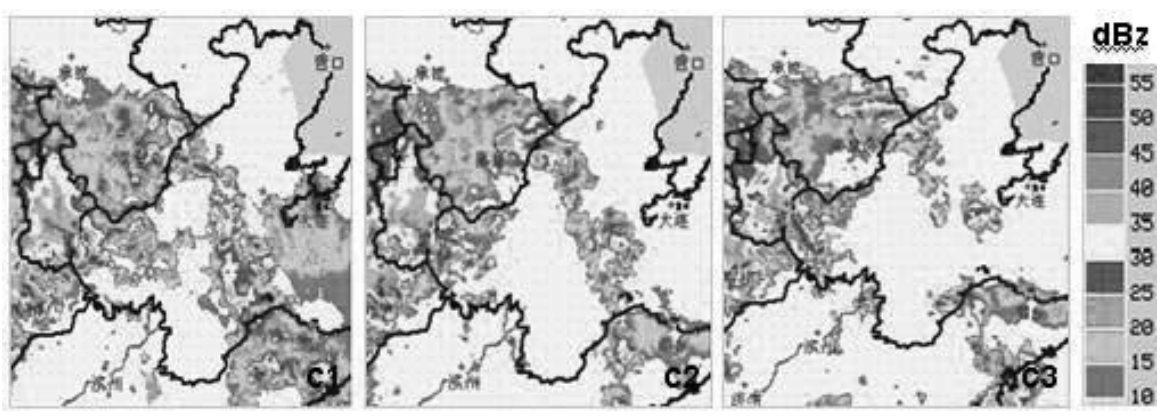

图 5.2015 年 9 月 1 日 02 时-04 时（CST）五部天气雷达基本反射率拼图，时间间隔 1 小时 
定能量增强, 在渤海中部的切变线附近诱发 多个中y、 $\beta$ 尺度强对流风暴单体，在雷达 回波“列车效应”下, 造成了秦皇岛近海新 一轮强对流天气过程。

（2）在渤海湾一带生成的多单体风暴稳定 少动, 15 时雷达反射率因子强回波带水平尺 度 $230 \times 80 \mathrm{~km}$, 强度 $40-50 \mathrm{dbz}$, 移向 $\mathrm{W} \rightarrow \mathrm{E}$ 向, 移速为 $20 \rightarrow 30 \mathrm{~km} / \mathrm{h}$, 对应天气短时强降水、 雷电等; 2 小时后东移莱州湾维持发展。

（3） 20 时渤海南部中尺度强对流回波带北 抬发展, 强回波带水平尺度 $350 \times 80 \mathrm{~km}$, 强度 $40-55 \mathrm{dbz}$, 移向 $\mathrm{SSW} \rightarrow \mathrm{NNE}$ 向, 移速为 $30 \rightarrow$ $40 \mathrm{~km} / \mathrm{h}$, 在渤海中部的切变线附近诱发多个 中y、 $\beta$ 尺度强对流风暴单体与主体回波带 移向成 90 o交角, 水平尺度 $30 \times 50 \mathrm{~km}$, 强度 $50-55 \mathrm{dbz}$, 移向 $\mathrm{SE} \rightarrow \mathrm{NW}$ 向, 移速为 $50 \rightarrow$ $60 \mathrm{~km} / \mathrm{h}$, 具有明显的向前传播线性特征, 即 雷达回波“列车效应”。03 时 (CST) 中部 海区回波带出现断裂, 强度下降至 30-40dBz，04 时趋于消亡。

基金项目:环渤海区域科技协同创新基金项 目 (黄渤海雷暴大风监测及预警指标研究 QYXM201502).

\section{参考文献}

[1] 丁一汇. 高等天气学. 北京: 气象出版 社, 2005:309-311.

［2］李延江等. 渤海强对流天气监测及概念 模型初建. 海洋预报, 2 013，30(4)： $45-51$.

[3] 卢焕珍, 赵玉洁, 俞小鼎. 雷达观测的渤 海湾海陆风辐合线与自动站资料的对 比分析.气象 2008, 34 (9) 57-64.

[4] 王彦, 李胜山, 郭立等. 渤海湾海风锋雷 达回波特征分析.气象，2006，32(12)： 23-28.

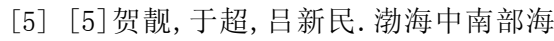
区一次雷暴大风过程分析. 海洋预报, 2011，28(1):19-24

［6］［6]郭庆利, 薛䶮波, 党英娜. 渤海海峡 雷雨大风的多普勒雷达回波特征. 海洋 预报, 2011, 28(1) : 13-18.

[7] 孙素琴, 郑婧, 支树林等. 一次由“列车 效应”引发的梅雨锋暴雨研究. 高原气
象, 2015, 34 (1) : 190-201.

[8] Guo S J. The Meteorological Disaster Risk Assessment Based on the Diffusion Mechanism. Journal of Risk Analysis and Crisis Response, 2012, 2(2): 124-130.

[9] Wang W, Zhou C, Du X. The Research of a Hail Risk Evaluation under Imperfect Information. Journal of Risk Analysis and Crisis Response, 2011, 1(2) : 133-141. 